\title{
ANTIREFLECTIVE VERTICAL STRUCTURE EXTENDED FOR ATTENUATION OF LOW FREQUENCY WAVES
}

\author{
J.A. Gonzalez-Escriva and J.R. Medina ${ }^{1}$
}

\begin{abstract}
A new maritime vertical structure based in the concept of multi-cell circuit (Medina et al., 2010) is presented to improve the antireflective performance for wave reflection of wind waves and oscillations associated with intense storms, resonance waves in port basins, etc. The large-scale laboratory results show a good performance of the multicell caisson tested, with less than $28 \%$ time for a $50 \%$ reduction in energy compared to the conventional one. Reflection coefficient is estimated for short waves in the range $65 \%$ to $90 \%$ increasing as frontal openings increase.
\end{abstract}

Keywords: vertical structure; antireflective; low frequency waves, multiple unit wave chambers, cell circuits

\section{INTRODUCTION}

Conventional vertical maritime structures with vertical faces are highly reflective structures whose wave energy amplification makes port operation difficult or even impossible. Because this phenomenon is conditioned by incident waves, port geometry and depth, any wave climate changes, port enlargements or dredging will modify the wave energy in the port area.

To attenuate wave reflection and the corresponding energy amplification in the nearby basin or floating area, a various structures have been designed, being Jarlan-type structures (Jarlan, 1961) the most widely used (see Fig. 1). A Jarlan-type structure consists of a perforated chamber which dissipates, basically, the wave energy by turbulence, friction and phase delay between the wave reflection on the front wall and the impermeable back wall. Jarlan-type structure experiments have been widely reported in the literature for short waves (wave period, $\mathrm{T}$, less than $25 \mathrm{~s}$ ), their results revealing a maximum antireflective efficiency for structures with an antireflective zone width, $\mathrm{B}$, almost a quarter of the wavelength, $L$, being even more effective with a multi-chamber design $\left(B_{1}+B_{2}>B\right)$.
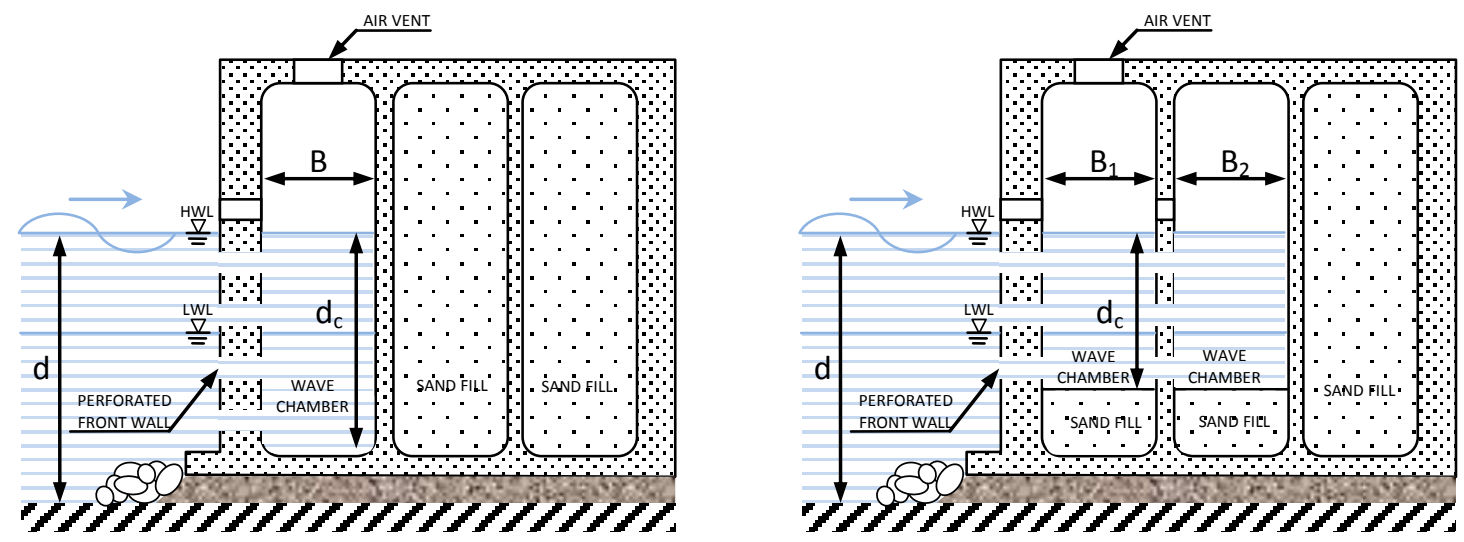

Figure 1. Jarlan-type structure with a) one chamber (left), b) two chambers (right).

However, all the existing antireflective solutions for vertical maritime structures have the drawback of their exiguous efficacy to reduce the reflection of low frequency waves ( $\mathrm{T}>25 \mathrm{~s}$ ). Low frequency basin oscillation is an infrequent but serious port problem and especially difficult to solve once the structure is in place. If the results for short waves could be applied to low frequency waves, the inadequateness of Jarlan-type solutions when facing low frequency waves would derive from the fact that the incident wave has a first reflection on the seawall-facing wall of the structure and the last reflection on the inner-end wall reached by the flow; if the roundtrip time of the flow between the frontal wall and the back wall is much less than one half of the incident wave period, the antireflective effectiveness is quite small. Therefore, a large space is needed for the antireflective zone which means high construction costs.

\footnotetext{
${ }^{1}$ Laboratory of Ports and Coasts, Universidad Politècnica de València, Camino de Vera s/n, 46022 Valencia, Spain.
} 
To overcome this technical problem, the design of a vertical structure can be based on a multi-cell circuit concept (Medina et al., 2010) which is considered to be especially effective to reduce the wave reflection of wind waves and oscillations associated with intense storms, resonance waves in port basins, etc., in vertical maritime structures with standard structure widths and construction methods.

\section{THE CONCEPT OF MULTI-CELL CIRCUIT}

The concept of a multi-cell circuit was developed in the CADIMA "Design and Adaptability of Conventional Caisson for Antireflective Breakwater and Quay Construction" research project (Martinez et al., 2010). This project allowed scientists, contractors and consultancy engineers to analyze not only the possible design solutions but their feasibility in the real world.

A circuit is defined as the space or pathway travelled by the flux of waves through a dissipation chamber from the incident point to the partial dissipation and/or exit from the attenuation system as a function of the established chamber characteristics. The constitution of large circuits in different directions within a caisson implicitly involves the horizontal separation of one circuit from the others, forcing the flux of water to be conducted along the circuit. The length of the dissipating chamber is then determined by the route length of the wave flow within the dissipating chamber between the frontal wall and the back wall, or half the length of the circuit of units if the chamber has two frontal openings and does not have a back wall.

Earlier studies have resulted in a design based on the multi-cell circuit concept, which includes different dissipation chambers that will implement the technical effect of Jarlan-type structures. As a novelty, the different dissipating chambers are extended horizontally forming circuits of several cells, along different directions, thus extending the pathway of the circulation of the flow induced by the waves and increasing the antireflectiveness for the lowest frequency waves (Garrido et al., 2010) without enlarging the width of the structure. Additionally, the design based on the multi-cell circuit offers a practical solution from the constructive point of view, as well as being economically viable (Martinez et al., 2010).

Assuming that the optimum technical antireflective effect of the Jarlan-type structure obtained $(\mathrm{B} \approx$ $\mathrm{L} / 4$ ) is applicable to low frequency waves, the use of the multi-cell circuit concept could provide an effective width for the antireflective zone, $\mathrm{B}_{\text {eff }}$, about $\mathrm{L} / 4$, equal to the length of the dissipating chamber, and higher than the caisson width.

As a result, having circuits of multiple units with longer or shorter lengths with the same antireflective zone width in breakwaters and quays, makes it possible to obtain optimum specific designs adapted to the local conditions in each stretch of the construction. For instance, the caissons used in a breakwater of a commercial port may have long circuits of multiple units, adequate to reduce the wave reflection of the most frequent and most intense wave storm in the year, which usually cause the port to be closed; the caissons used in quays more exposed to the wind waves which penetrate through the port entrance may have shorter circuits of multiple units, adequate to reduce the wave reflection of the wave storms which cause the maximum inner port agitation every year and finally, the caissons located in the most sheltered areas of the port may have much longer circuits of multiple units, adequate to reduce the wave reflection of the long waves associated with the wave groups of the storms, the port basin resonance and other low frequency waves. In other words, instead of being forced to use in practice the same solution for all situations, dissipating chambers with multiple units allow adequate wave reflection reduction in each stretch of the breakwater or quay of a port without enlarging the width of the antireflective zone.

\section{New design: Low frequency antireflective cyes- $R$ caisson}

Based on the multi-cell circuit concept, a caisson for antireflective quays was designed for low frequency attenuation $(40 \mathrm{~s}<\mathrm{T}<200 \mathrm{~s})$ related to port resonance phenomenon. Fig. 1 represents the cross section of the cyes- $R$ caisson in typical Mediterranean conditions, while Fig. 2 depicts a general view of the pathways defined by the circuits.

The two openings on the seaward-facing wall of the structure allow water to enter into the dissipation chambers defined by the interconnected cells. The water pathways extend horizontally forming circuits of 23 cells with more than two changes in the direction of circulation and with the length of each dissipation chamber being greater than the width of the antireflective zone of the structure. 


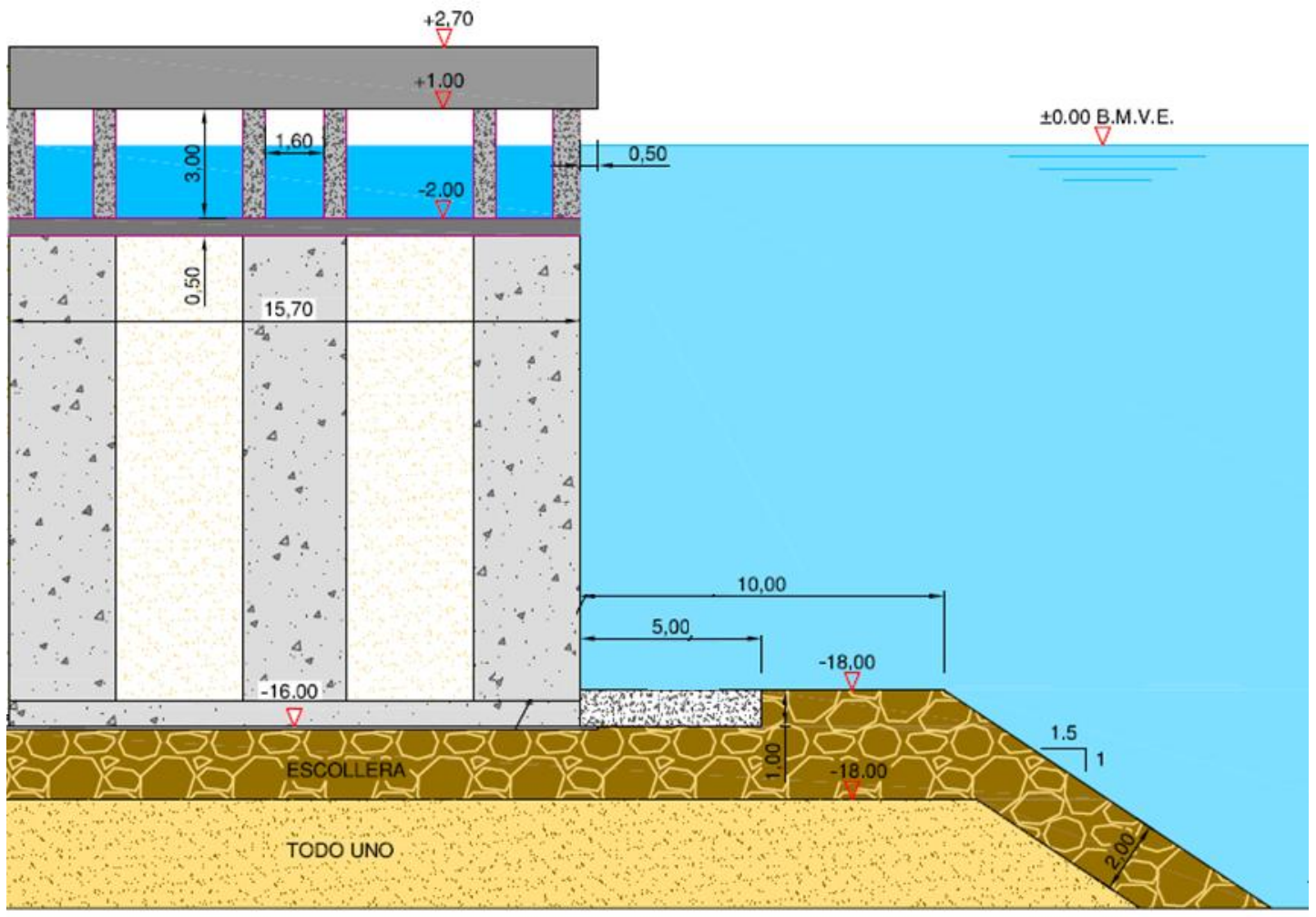

Figure 2. Cross section of the antireflective cyes- $R$ caisson designed for $60 \mathrm{~s}<\mathrm{T}<200 \mathrm{~s}$.

The specifically designed cell connectivity (circuits) for a $\mathrm{B}_{\mathrm{eff}} \approx \mathrm{L} / 4$ defines the two circuits of 23 cells with one frontal opening each. The effective width of the antireflective zone in the cyes- $R$ caisson theoretically extends up to 4 times the width of the antireflective zone of a caisson in a Jarlan-type structure, enhancing the absorbing capabilities of a caisson to the range of low frequency waves.

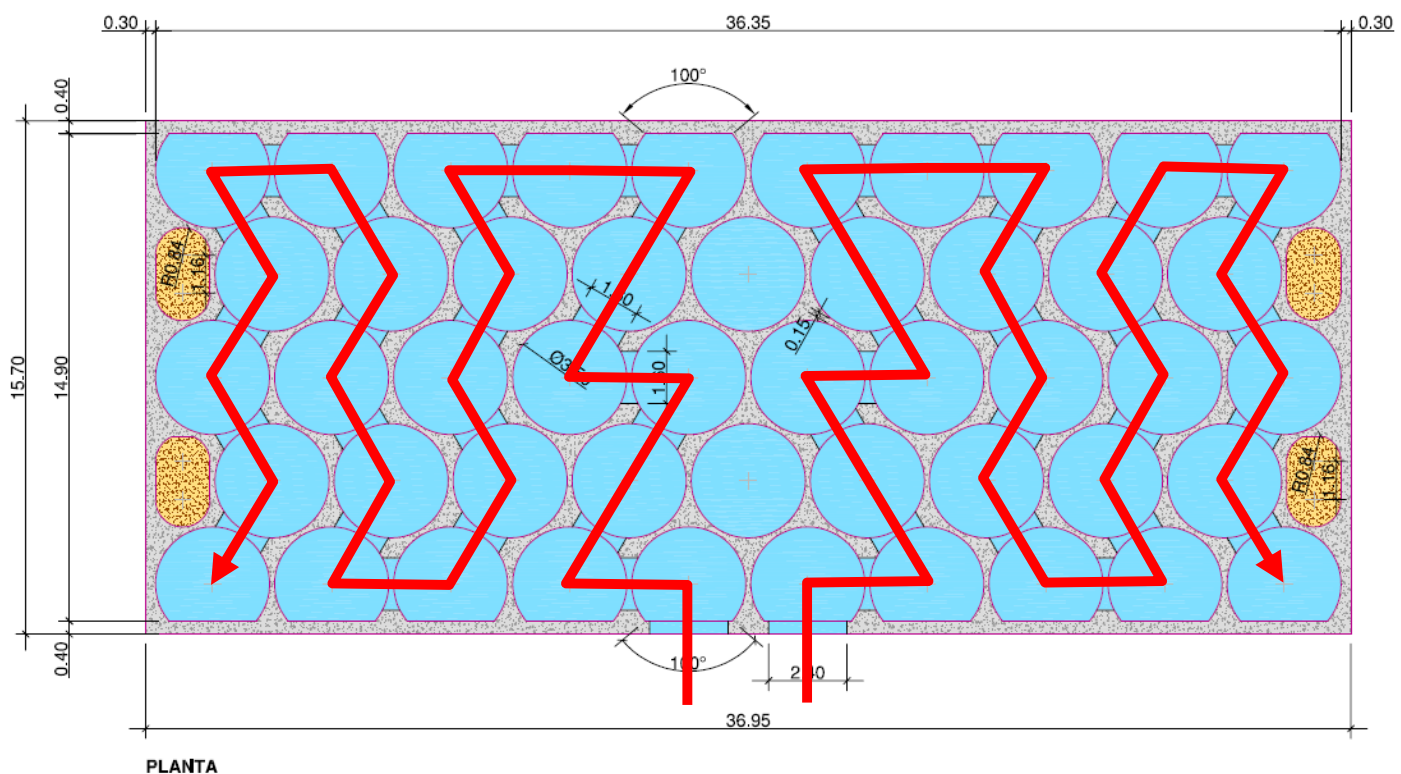

Figure 3. General view of the antireflective cyes- $R$ caisson with two circuits of 23 cells each. 


\section{LOW FREQUENCY WAVE ABSORPTION ANALYSIS OF THE cyes-R CAISSON}

In general studies, to identify the possible low frequency oscillations and wave energy amplification produced by reflection consider the wave climate, port geometry including antireflective features and water depth. While very simple geometries can be estimated in theoretical studies, numerical and physical scale models can provide useful data for more complex sheltered areas. However, the reflection coefficient of each maritime structure is needed, typically obtained using physical scale experimentation in laboratory.

Moreover, studies of the features of an antireflective structure exposed to low frequency waves have additional shortcomings:

1. Complex wave generation, due to the length of the waves that would require large strokes for the wave paddle or reduced wave paddle velocity beyond the usual ranges.

2. The inability of wave reflection analysis to separate incident and reflected waves when the wavelength is longer than the flume length.

3. Viscous phenomena, which could result in scale effects in small-scale models. Large-scale models are required because there is no previous research done in this area.

4. The lack of experimental methodology or analytical techniques previously reported in the literature, so both initially must be developed.

To this end and in order to validate the new design with a new experimental methodology and analytical technique, in this research, experiments were conducted with a large-scale model, and specific requirements were proposed.

\section{Experimental methodology and specific requirements of the facility and scale model}

A new methodology was established to assess the effectiveness of the a new vertical maritime structure against low frequency waves. Each test had an initial accumulative process in terms of energy which was achieved by generating small amplitude waves with a period equal to the period of the main resonance modes of the basin created between the wave paddle and the maritime vertical structure. The wave generation was stopped before the accumulative process made the water level exceed the crest of the caisson or when the wave height remained stable without an increase in energy. The subsequent damping process was measured to record any significant reduction in energy.

In Fig. 4, the solid line depicts the expected amount of accumulated energy (measured in terms of the sum of square water heights, $\Sigma \mathrm{H}^{2}$ ) of the conventional (impermeable) vertical structure, and the broken line represents the expected energy time variation for the antireflective cyes- $R$ caisson. Theoretically, in an ideal system with no friction and no water leakage, the energy increases as the wave paddle moves, stopping growth as the paddle does, the wave energy remaining constant for the conventional vertical structure and diminishing for the antireflective solution.

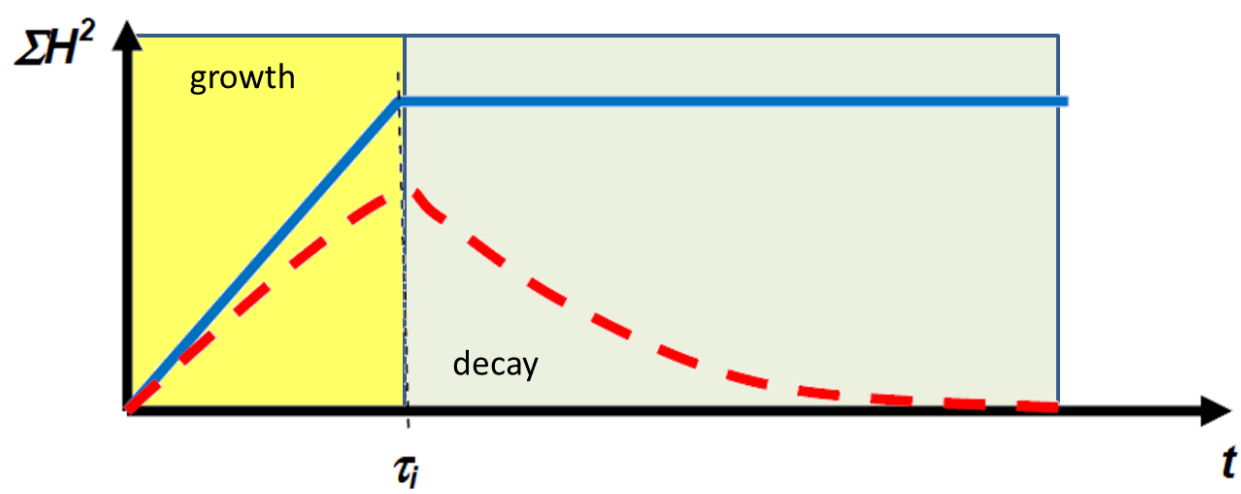

Figure 4. Expected energy time series in the low frequency experiments of the conventional vertical structure and the antireflective cyes- $R$ caisson (ideal system).

Besides the effect of the antireflective structure, in laboratory experiments, friction with side walls, bottom, structure toe, wave paddle, etc., is expected to contribute to reducing energy in the same way for both structures. Thus, the decay of the conventional vertical structure, as a reference, and the antireflective structure can be used to compare the antireflective features of the new solution. 
The facility must meet special requirements and a scale model is needed to implement the new experimental methodology and analysis:

- to avoid viscous scale effects, the flow inside the antireflective structure model must be turbulent for non-breaking conditions (a scale of 1/12 was calculated as the minimum for the range of velocities to be tested).

- $\quad$ to prevent leakages, the wave paddle must be watertight.

- to guarantee that all the energy is contained within the volume limited between the wave paddle and the vertical maritime structure (laboratory basin), all the elements were sealed to avoid water leakage including the floor, walls and rubble foundation, so that the decay process depended only on the antireflective structure and the friction to the walls and floor of the flume.

- to allow the accumulation of energy in the laboratory basin, the active absorption systems must be disconnected.

- $\quad$ to produce the maximum resonance, wave periods must be coincident to the resonance periods for the flume limited by the wave paddle and the model. Wave heights must be of small amplitude to prevent early overtopping.

- no overtopping is accepted as reducing energy in the system.

\section{Large-scale testing}

2D experiments were carried out in the large wave flume $(90 \mathrm{~m}$ long, $3.6 \mathrm{~m}$ wide and 6.0 to $4.5 \mathrm{~m}$ deep) in the Centre for Ports and Coastal Studies of the CEDEX (Centre for Public Works Studies and Experimentation). Test were conducted with a 1/11.6 large-scale model of the caisson cyes- $R$ (A), and with two additional vertical antireflective caissons cyes- $R$ (D and T), represented in Fig. 5 and an impermeable one, all founded on a rubble mound structure (see Fig. 2).

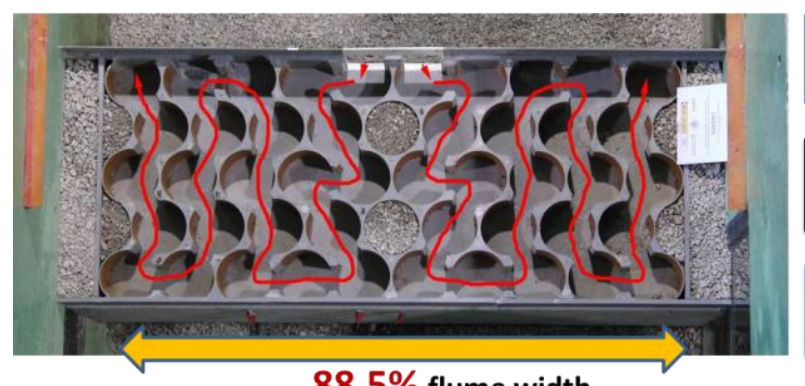

$88.5 \%$ flume width

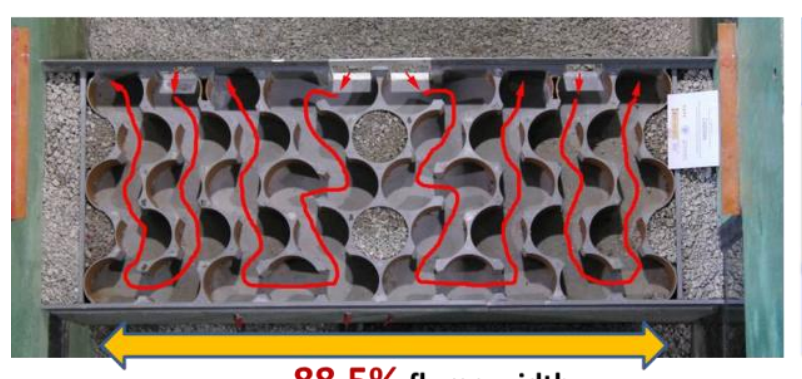

$88.5 \%$ flume width

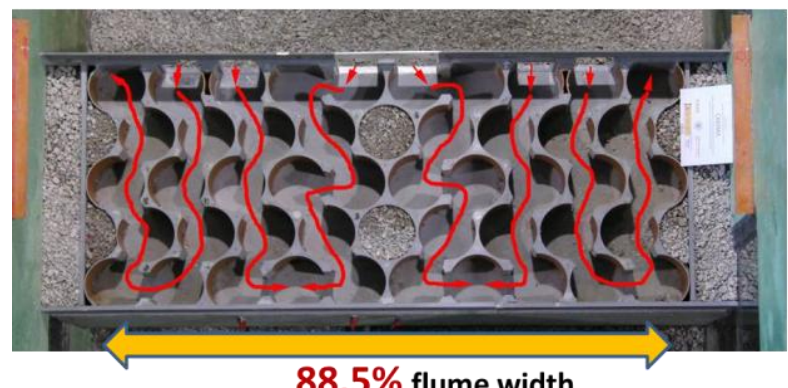

$88.5 \%$ flume width

\section{cyes-R " $A$ " type}

2 circuits of 23 cells each 1 frontal opening per circuit

Specifically designed for $\mathrm{T}=90 \mathrm{~s}$
cyes-R “D” type

2 circuits of 10 cells each $+$

2 circuits of 13 cells each 1 frontal opening per circuit Specifically designed for $\mathrm{T}=45 \mathrm{~s}$

Figure 5. Typologies tested for the antireflective cyes- $R$ caisson. 
The facility at the CEDEX fulfills all the methodological requirements: the wave paddle is watertight; the scale is larger than $1 / 12$, and the active absorption system can be disconnected. The model and bottom of the flume were sealed to become watertight. The water was not allowed to pass through the model to the back side of the flume. Fig. 6 shows that neither wave paddle nor model had water leakages.
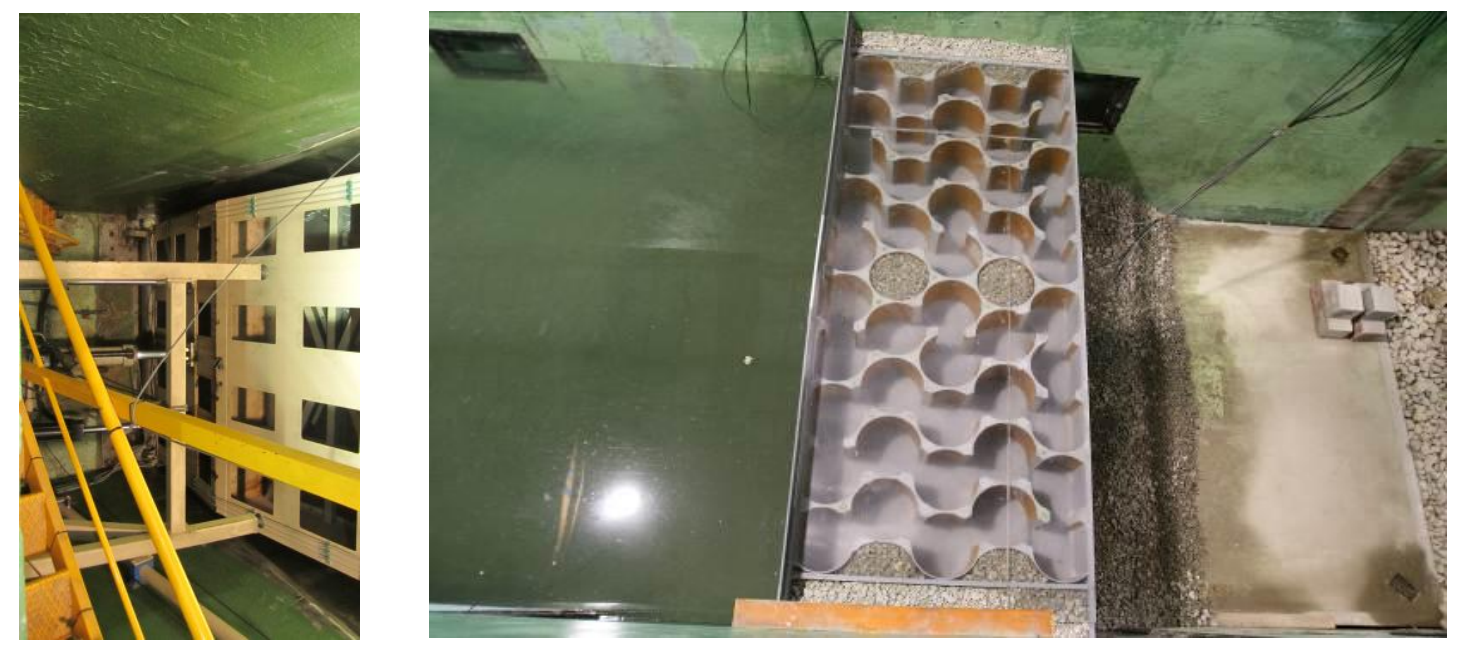

Figure 6. Absence of water leakages: a) wave paddle with interior face completely dry (left), b) model of the cyes- $R$ with water on the left and dry (right).

Irregular and regular conventional short wave tests were conducted along with the specific low frequency tests for a better characterization of the cyes- $R$ antireflective features even for wave conditions that they surely will be exposed to but that were not included in the design. Table 1 specifies the test matrix used.

\begin{tabular}{|c|c|c|c|c|c|}
\hline \multirow{2}{*}{ Type of tests } & \multirow{2}{*}{ Parameters } & \multicolumn{4}{|c|}{ Typology tested } \\
\hline & & conventional & cyes- $R(\mathrm{~A})$ & cyes- $R(\mathrm{D})$ & cyes- $R(\mathrm{~T})$ \\
\hline Low frequency & $\begin{array}{l}\text { Wave period, } \mathrm{T} \\
\text { Wave height, } \mathrm{H} \\
\text { Water level, } \mathrm{WL}\end{array}$ & $45 \mathrm{~s}, 90 \mathrm{~s}$ and & $\begin{array}{r}\text { (natural res } \\
0.7 \mathrm{r}\end{array}$ & $\begin{array}{l}\text { ce periods of } \\
1.2 \mathrm{~m}\end{array}$ & boratory basin) \\
\hline Short waves & $\begin{array}{l}\text { Wave period, } \mathrm{T}_{\mathrm{p}} \\
\text { Wave height, } \mathrm{H} \\
\text { Water level, } \mathrm{WL}\end{array}$ & & $6 \mathrm{~s}, 1$ & nd $20 \mathrm{~s}$ & \\
\hline
\end{tabular}

The instrumental sketch is depicted in Fig. 7. Two groups of three resistance wave gauges each were located by the wave paddle and another between the bottom slope and the model. One ultrasound wave gauge was located by the first group of resistance wave gauges; three were located by the second group and two by the model. In addition to the instruments assembled, two video cameras were installed to record all the experiments.

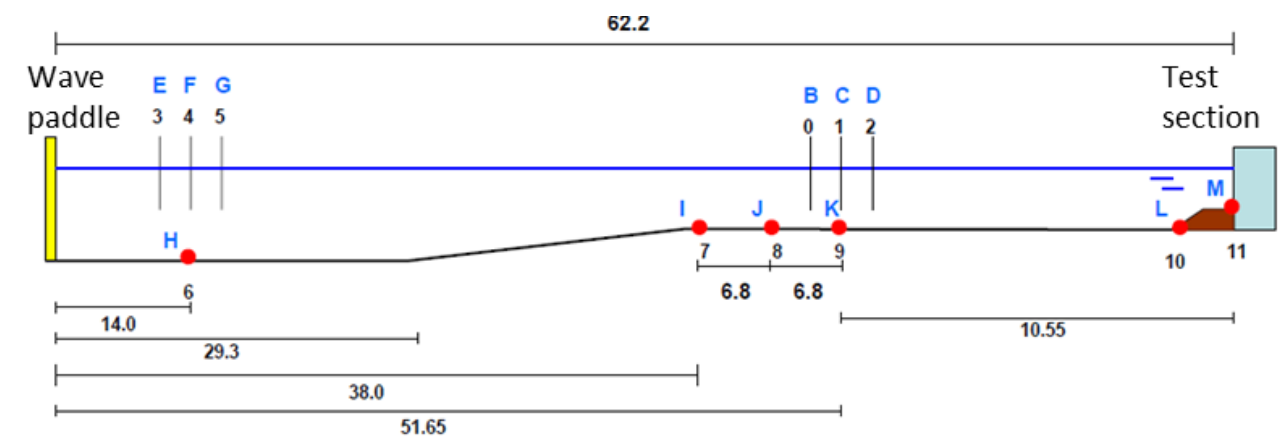

Figure 7. Experimental sketch. Vertical lines $=$ resistance wave gauges. Red dots $=$ ultrasound wave gauges. 


\section{Large-scale results}

Basic spectral analysis was performed corroborating energy accumulation in the resonant modes (45 s and $90 \mathrm{~s}$ ). Fig. 8 shows an example of the results for the low frequency test with $\mathrm{T}=135 \mathrm{~s}$.

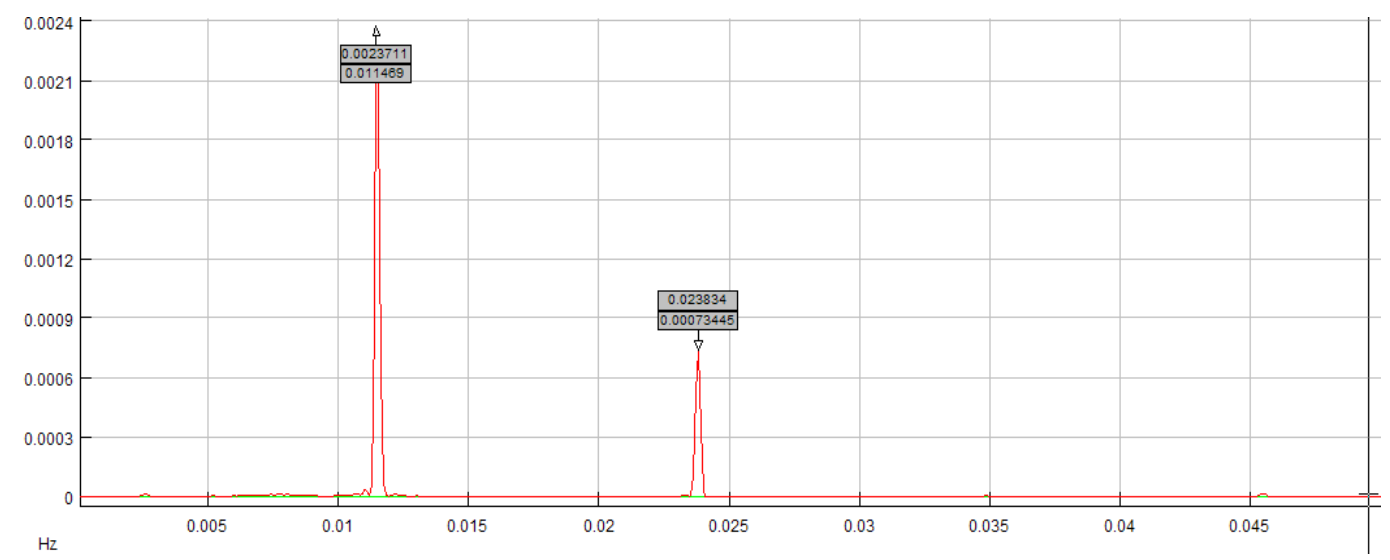

Figure 8. Energy spectrum of a low frequency test with $\mathrm{T}=135 \mathrm{~s}$.

Typical measurements of a wave gauge in the vicinity of the vertical structure for the resonant period T=90 s are depicted in Fig. 9 for the four typologies tested. As expected, the cyes- $R$ (A) caisson, which was specifically designed to be optimum at that period, appears the most effective in absorbing wave energy, while the conventional vertical structure features very low energy damping over time. A close-up view of the elevation time series for the cyes- $R(\mathrm{~A})$ is compared to conventional vertical structure in Fig. 10.
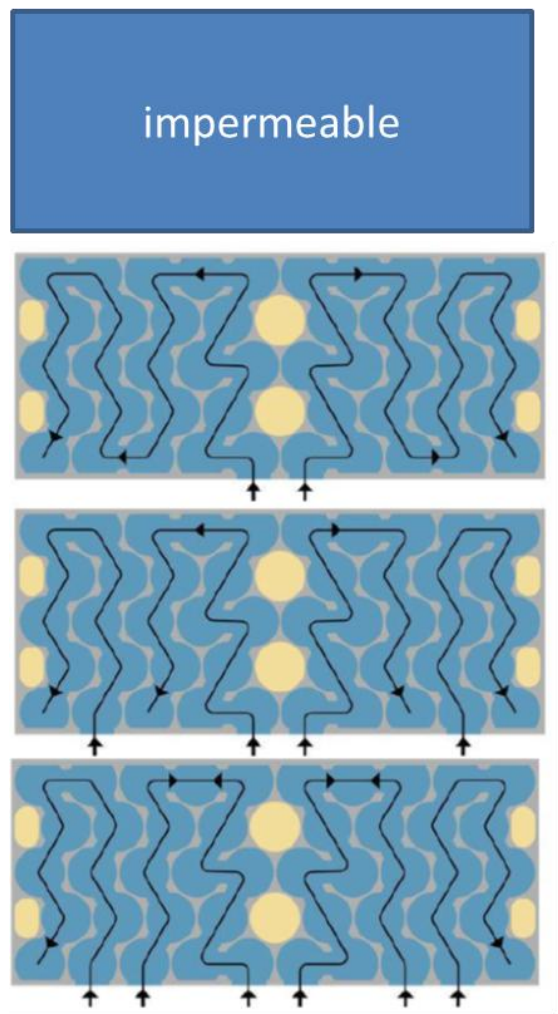
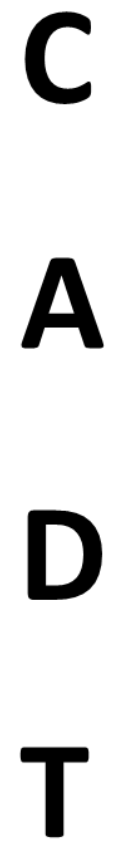

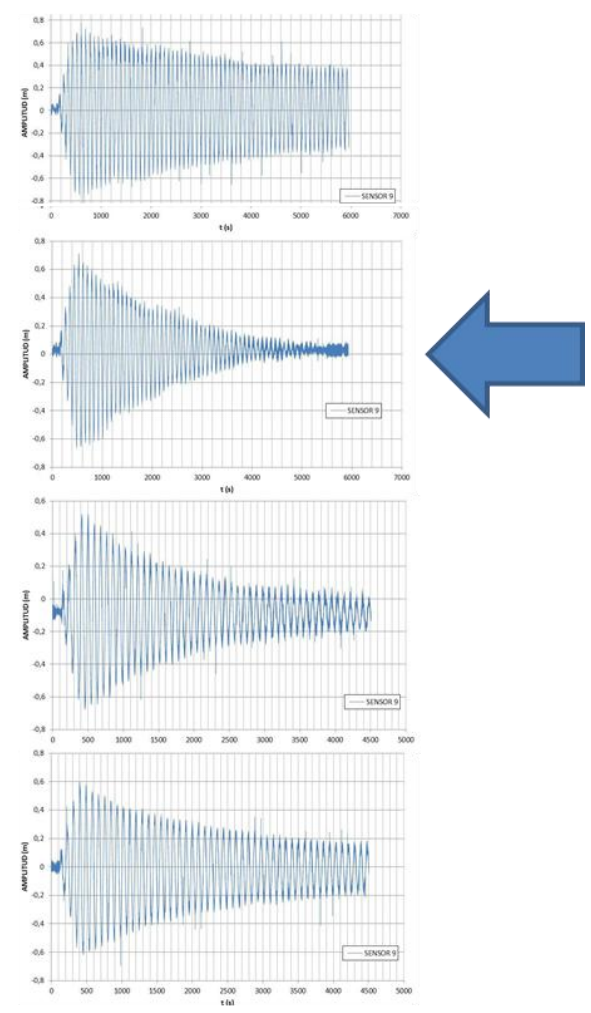

Figure 9. Time series of water elevations for the low frequency tests with $\mathrm{T}=90 \mathrm{~s}$ for the four typologies tested. 


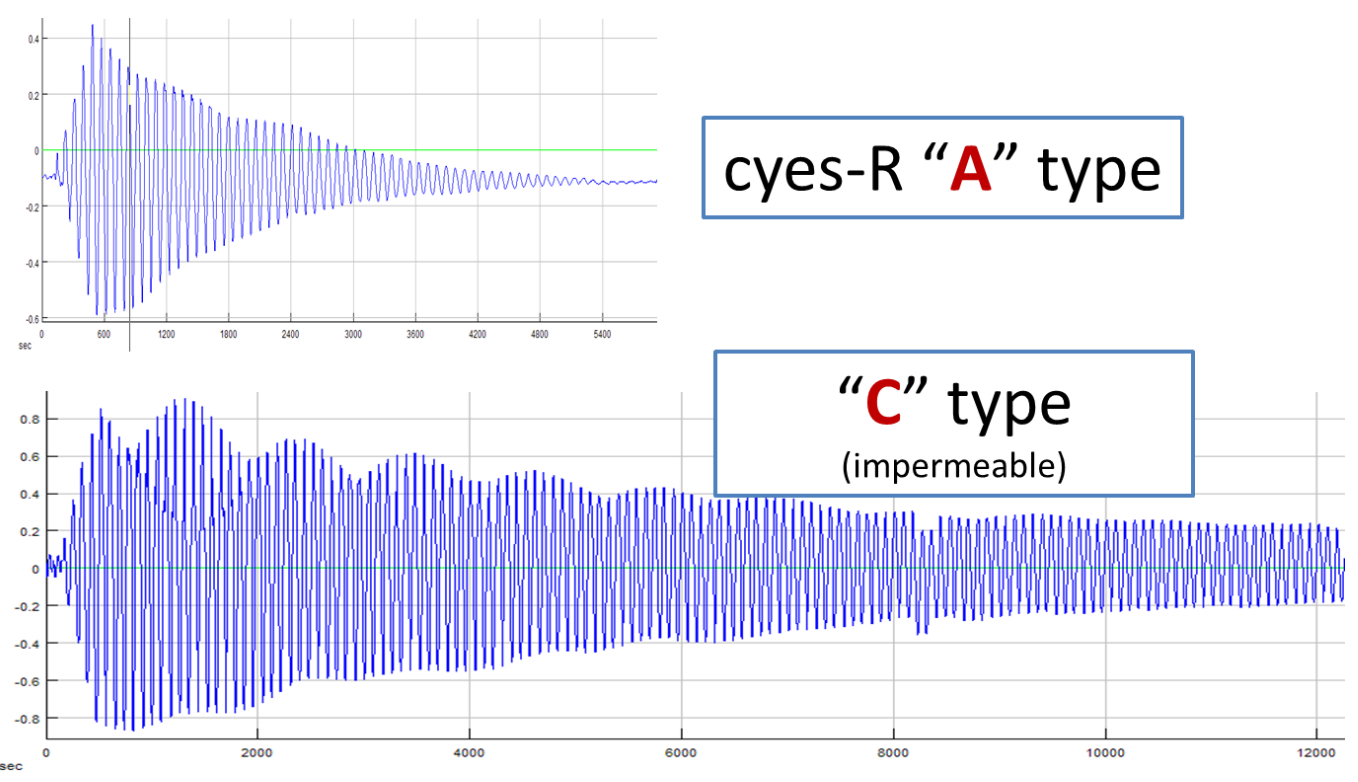

Figure 10. Time series of water elevation for the low frequency tests with $\mathrm{T}=90 \mathrm{~s}$, of the cyes-R (A) caisson (upper graph) and for the conventional vertical section (lower graph).

Wave energy in the time domain can be estimated with the square of the water elevation smoothed with a Barlett triangular window. Two wave amplitudes per typology and per period are depicted in Fig. 11 for each of the four typologies tested. Again, large differences in the decay are observed for the antireflective cyes- $R$ caissons compared to the conventional vertical structure.

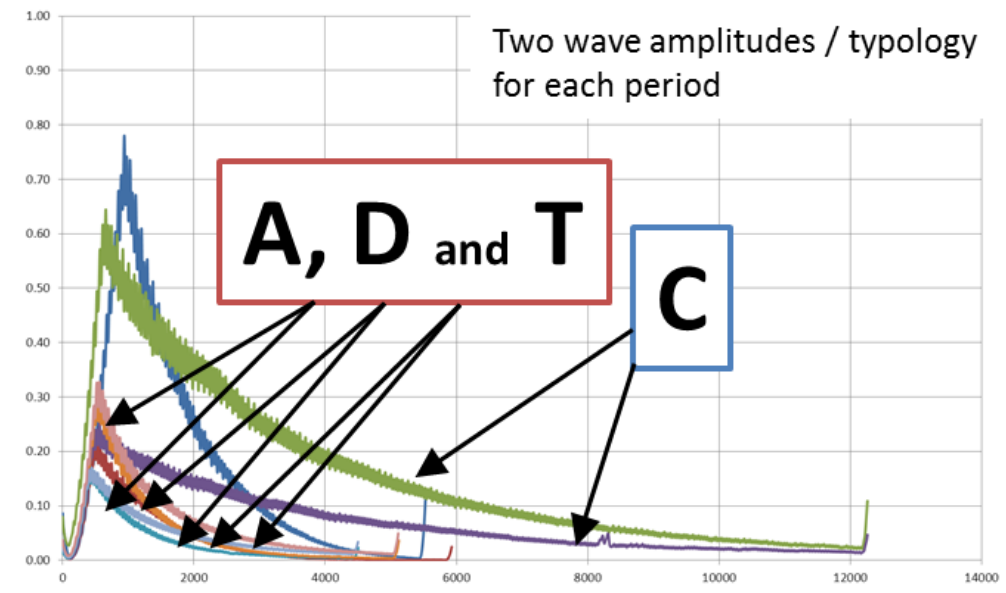

Figure 11. Time series of the estimated wave energy for the low frequency tests with $T=90 \mathrm{~s}$.

Exponential energy decay can be used to obtain the time required for a 50\% reduction in energy compared to the energy when the decay started ("half energy life"). The results of the half energy life (in prototype seconds) for the low frequency wave experiments are represented in Table 2.

\begin{tabular}{|c|c|c|c|c|}
\hline \multicolumn{5}{|c|}{ Table 2. Half energy life for the typologies and periods tested. } \\
\hline $\begin{array}{c}\text { LF period, } \\
\mathrm{T}\end{array}$ & \multicolumn{4}{|c|}{ Typology tested } \\
\cline { 2 - 5 } & conventional & $\begin{array}{c}\text { cyes- } R \\
(\mathrm{~A})\end{array}$ & $\begin{array}{c}\text { cyes- } R \\
\text { (D) }\end{array}$ & $\begin{array}{c}\text { cyes- } R \\
(\mathrm{~T})\end{array}$ \\
\hline $45 \mathrm{~s}$ & $903 \mathrm{~s}$ & $477 \mathrm{~s}$ & $203 \mathrm{~s}$ & $206 \mathrm{~s}$ \\
\hline $90 \mathrm{~s}$ & $2100 \mathrm{~s}$ & $693 \mathrm{~s}$ & $533 \mathrm{~s}$ & $730 \mathrm{~s}$ \\
\hline $135 \mathrm{~s}$ & $2666 \mathrm{~s}$ & $578 \mathrm{~s}$ & - & - \\
\hline
\end{tabular}


For the short waves tested, reflection coefficients from 60 to $90 \%$ were obtained. Increasing the openings in the frontal face of the caisson improved the antireflective effectiveness for short waves.

\section{CONCLUSIONS}

Port basin resonance due to quay reflection, associated to low frequency waves $(40 \mathrm{~s}<\mathrm{T}<200 \mathrm{~s})$, is an uncommon but still unsolved problem. The concept of multi-cell circuit extended the best antireflective $\mathrm{B} / \mathrm{L}$ results in standard Jarlan-type caissons which were subjected to low frequency waves (by enlarging the effective width of the antireflective zone, $\mathrm{B}_{\text {eff }}$ ). Moreover, the quay design can be adapted to achieve the adequate wave reflection reduction in each stretch of the vertical structure or port without enlarging the width of the structure.

Based on the multi-cell circuit, the new antireflective solution for low frequency waves, $c y e s-R$, is presented with long multi-cell circuits being created within the structure. These long circuits defined dissipation chambers with more than two changes in the direction of circulation and each one larger than the width of the antireflective zone of the structure (width of the structure as a maximum).

A new wave energy accumulation methodology was used to validate the effectiveness of the circuitbased solution in antireflective caissons under low frequency wave action. Each test had an accumulative process in terms of energy achieved through the generation of small amplitude waves (stopped smoothly before overtopping) with a period equal to the period of the main resonance modes of the experimental basin (volume limited between the wave paddle and the vertical maritime structure within the wave flume). Active absorption must be disconnected to allow accumulative process. Moreover, the elements limiting the volume of water between the wave paddle and the vertical maritime structure must be watertight including the floor, walls and rubble foundation (laboratory basin) to prevent energy dissipation other than that produced by the antireflective structure.

2D experiments were carried out in the large wave flume $(90 \mathrm{~m}$ long, $3.6 \mathrm{~m}$ wide and 6.0 to $4.5 \mathrm{~m}$ deep) in the Centre for Ports and Coastal Studies of the CEDEX (Centre for Public Works Studies and Experimentation) testing a 1/11.6 large-scale model of the caisson cyes- $R(\mathrm{~A})$ as well as two additional vertical antireflective caissons cyes- $R(\mathrm{D}$ and $\mathrm{T}$ ) and an impermeable one, all founded on a rubble mound structure.

The laboratory results show a good performance of the multi-cell caisson tested, with a time for a $50 \%$ reduction in energy compared to the energy when the decay started ("half energy life") less than 3.5 times for the caisson cyes- $R$ (A) compared to the conventional one.

Reflection coefficient, $\mathrm{K}_{\mathrm{r}}$, is estimated for short waves in the range $65 \%<\mathrm{Kr}<90 \%$ increasing as frontal openings increase.

\section{ACKNOWLEDGMENTS}

The authors received support from the CADIMA (2009-2011) project, sponsored by to the Spanish Ministries of Development, Science and Innovation. The authors are grateful to Dr. Debra Westall for revising the manuscript.

\section{REFERENCES}

Garrido, J., D. Ponce, A. Berruguete, S. Martinez, J. Manuel, L. Fort, D. Yagüe, J.A. Gonzalez-Escriva, and J.R. Medina. 2010. Study of Reflection of New Low-Reflectivity Quay Wall Caisson, Proceedings of $32^{\text {nd }}$ International Conference on Coastal Engineering, ASCE, 466-480.

Jarlan, G. E. 1961. A perforated vertical breakwater, The Dock and Harbour Authority, Vol. 21, nº486, 394-398.

Martinez, S., J. Manuel, D. Yagüe, J. Garrido, D. Ponce de Leon, A. Berruguete, J.A. Gonzalez-Escriva and J.R. Medina. 2010. Designing a New Low-Reflexivity Quay Wall Caisson, Proceedings of the $32^{\text {nd }}$ PIANC Congress, 949-963.

Medina, J.R., J.A. Gonzalez-Escriva, L. Fort, S. Martinez, D. Ponce de Leon, J. Manuel, D. Yagüe, J. Garrido and A. Berruguete. 2010. Vertical Maritime Structure with Multiple Chambers for Attenuation of Wave Reflection, International PCT/EP2010/068000, EPO, The Hague, 23 pp. 